\title{
L'ALCANÍCIA DE BENIFALLET
}

Per

VENTURA CASTELLVELL

L'aparició de l'article sobre els topònims derivats de «kanîsa», escrit per Míkel de Epalza a la «Miscel.lània d'homenatge a Enric Moreu-Rey» (1), m'ha impulsat a escriure aquestes notes sobre l'Alcanícia, antic nom d'una partida del terme de Benifallet (Baix Ebre).

El topònim Alcanícia, derivat del mot àrab «kanîsa» (2), apareix documentat a Benifallet en diverses ocasions entre l'any 1200 i el 1487. La referència más antiga correspon a l'any 1200 i la trobem entre la documentació de la Comanda del Temple de Tortosa que hi ha a l'Arxiu de la Corona d'Aragó. Es tracta d'una permuta de terres entre Elisenda $i$ el seu marit Berenguer Gula, per una banda, i els frares del Temple per l'altra, i diu així:

«... in termino de Benhaleto in valle de Alchanitia, qui vocatur ortus de Alochaiba...» (3).

En el capbreu de Benifallet de l'any 1373 torna a aparèixer aquest topònim (4). En aquesta ocasió se'l cita en vuit ocasions. Entre els declarants n'hi ha sis de sarraïns i dos de cristians:

(1) MÍKEL DE EPALZA: Els mossàrabs valencians i els topònims derivats de „kanísa" àrab, dins de la Miscel.lània d'homenatge a Enric Moreu-Rey, volum li, pp. 149-153. Publicacions de l'Abadia de Montserrat, Barcelona, 1988.

(2) Sobre el seu significat, l'article citat anteriorment ens informe que és més ampli que el de simple «església cristiana" (pàgina 150). També hi podem trobar informació bibliogràfica sobre «kanîsa» i els seus derivats.

(3) Arxiu de la Corona d'Aragó, secció 5, armari IV, volum III, doc. 234, fol. 72, del 13 de febrer de 1200. La cita està treta del llibre de L. PAGAROLES: La Comanda del Temple de Tortosa: primer periode (1148-1231), de la Col.lecció Dertosa, n. ${ }^{\circ}$ 16, pàgina 305, Tortosa, 1984.

(4) Arxiu de la Corona d'Aragó, Battlia General, classe 2. ${ }^{a}$. Bi 1. Es tracta d'un capbreu de terres, feus i regalies de Tortosa de l'any 1373, dedicat majoritàriament a Benifallet. A partir d'ara indicaré «Capbreu 1373 ". 
«... una sort de terra campa la qual es en la partida dalcanicia...» (5).

«... una sort de terra campa ab oliveres en la partida appellada Alcanicia...» (6).

«... en la partida de Alcaniçia que es damunt la Vila una sort de terra campa ab oliveres et carrovers... affronta duna part ab la heretat dena Castelleta...» (7).

«... manifesta que ha en la partida dalcanicia una sort de terra campa... affronta a una sort den salvador dela altra ab terra campa den xico dela altra ab terra campa den Cotenti...» (8)

«... hun troç de terra campa que ha alcaniçia...» (9).

«... una sort de olivar que ha en la partida daicanicia...» (10).

«... una sort de terra campa que ha Alcanicia afronta ab la heretat den castellet...»(11).

«... un troç de terra campa ab oliveres e carrovers e malgraners que ha en Alcanicia...» (12).

En el capbreu de Benifallet de l'any 1487 apareix citada només en una ocasió, referint-se a una petita propietat:

«... set oliveres en la partida dalcanysia...» (13).

Aquí s'acaba la informació documental d'aquesta Alcanícia de Benifallet. Cal observar que les referències han anat minvat clarament d'un capbreu a l'altre: de vuit citacions en el de 1373 a una en el de 1487. En els posteriors capbreus dels segles XVI i XVII ja no surt (14). Es per això que podem donar per perdut aquest topònim en el segle XVI.

Per conèixer la situació geogràfica d'aquesta partida caldrà que repasem la informació que posseïm. Es tracta d'una vall, _-«in valle de Alchanitia»--, que es regava, - «qui vocatur ortus de Alochaiba» -, i que estava situada riu amunt, -«que es damunt la vila»-. El poble de Benifallet està a la riba esquerra del riu Ebre, per tant la partida d'Alcanícia es trobava en aquest mateix cantó. En cas contrari s'indicaria amb un «dellà l'aigua» o similar. Aquestes dades no ens concreten el lloc, però redueixen les possibilitats dintre de l'extens terme de Benifallet. Crec, no obstant, que és suficient perquè ens fixem en un indret precís, conegut actualment amb el nom de l'Areneta, a mig quilòmetre del poble, riu amunt, on es troben restes d'antigues

(5) Capbreu 1373, fol. 51.

(6) Capbreu 1373 , fol. 65.

(7) Capbreu 1373 , fol. 68 .

(8) Capbreu 1373, fol. 79.

(9) Capbreu 1373, fol. 93 .

(10) Capbreu 1373 , fol. 94.

(11) Capbreu 1373, fol. 114.

(12) Capbreu 1373 , fol. 115.

(13) Arxiu de la Corona d'Aragó, Batllia General, classe 2. a Bi 1. "Capbreu de censos i altres drets que reberen en lo territori de Tortosa», dels anys 1487 i 1488 , fol. 56 . Més de la meitat d'aquest capbreu està dedicat a Benifallet; la resta es reparteix entre Aldover, Amposta, Tortosa, Xerta, Ulldecona, Godall, Tivenys i Santa Maria de Benifassà.

(14) He consultat els següents capbreus dels segles XVI i XVII relacionats amb Benifallet, tots ells de I'Arxiu de la Corona d'Aragó, Batllia General, classe 2. a: Bi 3: «Capbreu del territori de Tortosa», anys 1589-1596; Bi 4: «Capbreu del territori de Tortosa», anys 1601-1640; Bi 7: «Capbreu de Tortosa i el seu territorim, any 1699. 


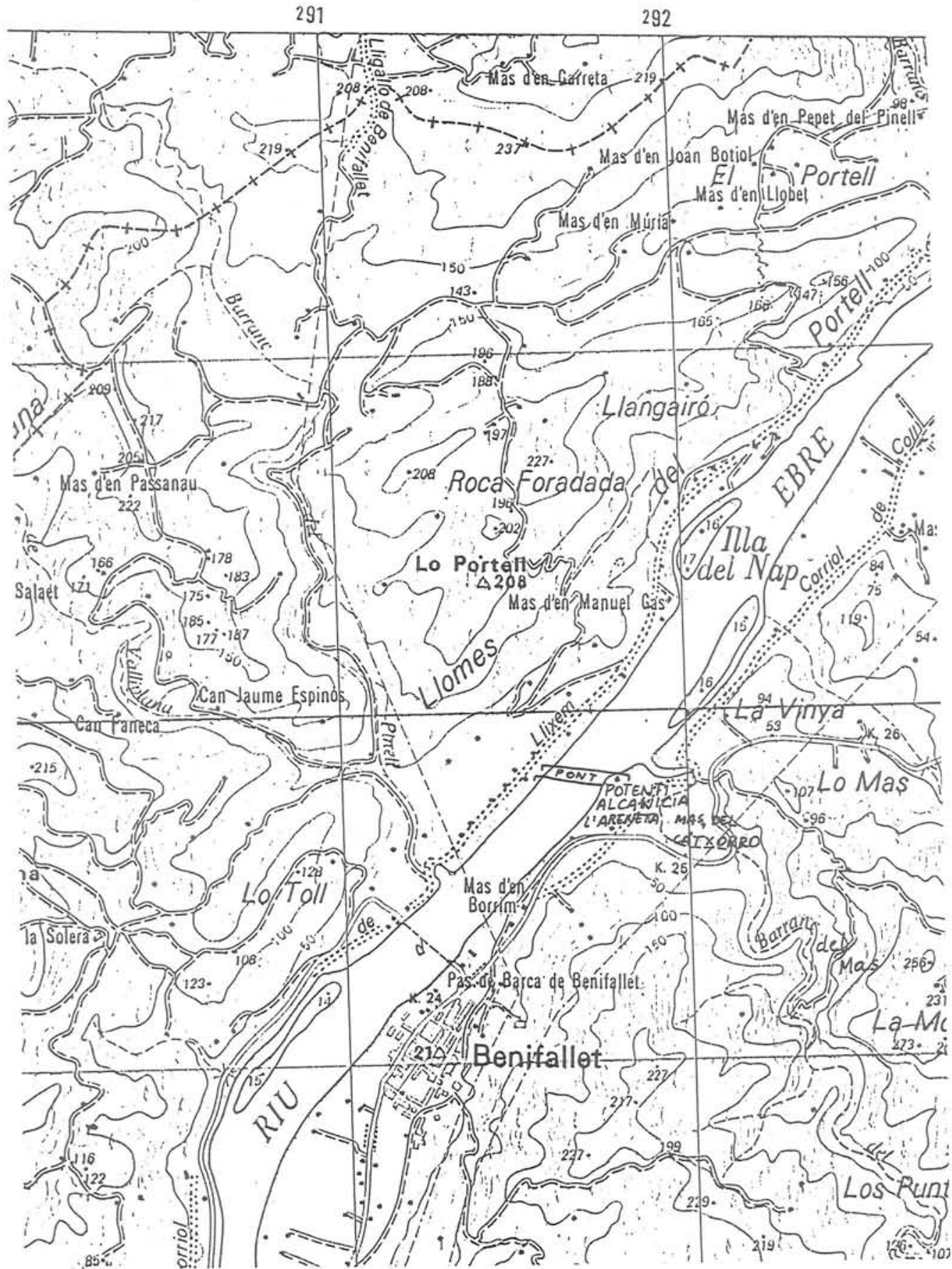


construccions conegudes de sempre per la gent d'aquestes terres. Un article a «La Veu de Tortosa» l'any 1902, va donar a conèixer aquest lloc més enllà del terme. L'escrit esmenta uns "paredons» que «ocupen una extensió bastant regular de terreno, dificil de senyalar, ja que está tot rublert y plantat, pero en totes direccions apareixen fragments de construccions romanes, tals com parets, paviments de formigó, trossos de teules, anfores, ampolles y alguns fragments de pedra molt parescuda á la toba d'Olot...». Més endavant segueixen aquestes ratlles: «La presencia de tals ruines y fragments de objectes d'época romana senyalen que'l nom de Benifallet podrá ser d'origen árabe, pero no axís s'antiga fundació, puig que abans que'ls árabes lo poblessin, los romans ja l'havien habitat, ..." (15).

Aquest és el probable lloc de l'Alcanícia. Ultimament, en aquest punt, s'han fet les obres necessàries per a bastir un pont que comuniqui les dues ribes del riu. Tot plegat acompanyat d'un gran moviment de terres. Precisament per aquí ha de passar l'anomenat «Eix de l'Ebre», important via de comunicació que ha d'unir la costa amb l'interior. Abans d'iniciar aquestes obres, es va fer una excavació d'urgència a la part més afectada. De moment no s'ha publicat cap informe sobre el resultat d'aquestes excavacions.

L'Areneta i les veines terres del Mas del Catxorro es troben prop del riu, al final del barranc del Mas i en un terreny lleugerament enclotat, formant una petita vall. L'indret no sempre he rebut els mateixos noms. A part del d'Alcanícia, la documentació n'indica uns quants que giren al voltant de «Castellet» (16) i «Morella» 0 «Morelleta». També el de «Potenti», nom encara viu. «Castellet» potser va néixer com a indicador de ruïnes, $i$ «Morella» $i$ «Morelleta» amb una clara referència a un possible origen moro:

$$
\begin{aligned}
& \text { «... Passador del Mas del Castellet...», de l'any } 1618 \text { (17). } \\
& \text { «Lo Mas dicho lo Castellet al Bajador de la Morella». Any } 1715 \text { (18). } \\
& \text { «Heredad de la Morelleta o Castellet llamado lo Mas». Any } 1726 \text { (19). }
\end{aligned}
$$

Enric Bayerri, a la seva monumental història de Tortosa i de la seva comarca, escriu: «En Benifallet priva la tradición de que la población primitiva estaba edificaba en el que se llama Collet de la Morelleta», nom que interpreten com a «moreria» (20). I encara més, en una enquesta toponímica realitzada fa uns tres anys per encàrrec de l'Institut Cartògràfic de Catalunya (21), s'indica que «la Muralleta» és el nom amb què coneixen a «casa el Catxorro» el lloc on estava l'antic poblat. Aquest últim exemple indica un canvi semàntic, convertint allò que semblava tenir un origen moro, en una construcció defensiva.

(15) La Veu de Tortosa, $n{ }^{\circ} 161$, del 21 de desembre de 1902, pàgines 2 i 3 . L'article és sobre una excursió del "Centro Excursioniste" de Tortosa feta poc temps abans. Va firmat només amb la lletra A. He mantingut l'ortografia original.

(16) A les cites 7 i 11 apareixen els antropónims «Castellet» $i$ «Castelleta» afrontant amb terres de l'Alcanicia

(17) Arxiu de la Corona d'Aragó, Batllia General, classe 2. a , Bi 4, fol. 129. Anys 1601 a 1640.

(18) Arxiu Históric de Tortosa. Capbreu de l'any 1715.

(19) Arxiu de la Corona d'Aragó, Batllia General, classe 2. ${ }^{a}$, JJ. 1, de l'any 1726, pàgina 219.

(20) ENRIC BAYERRI: Historia de Tortosa y su comarca, volum IV, pàgina 456. En total són VIII volums editats a Tortcsa per Algueró i Baiges entre els anys 1933 i 1960.

(21) Enquesta realitzada per un grup de joves de Benifallet i coordinada per JOAN SALVADOR VENTURA. 
A l'Areneta, a la part no afectada per les obres del pont, encara es pot veure el que resta d'aquest antic poblament. Hi destaca una enorme roca treballada, fixada a terra i que mai s'ha pogut moure. Alguns creuen que és un contrapès d'algun antiquíssim molí. Al seu costat hi ha una necròpolis. Tant la roca com la necròpolis tenen, per als habitants de Benifallet, un origen àrab (22).

La presència d'aquest cementiri ens fa tornar de nou al capbreu de l'any 1373, que tan sovint ens cita el topònim Alcanícia. En un dels casos - cita 8-, llegim: «a partida dalcanicia» afronta, entre altres heretats, «ab terra campa den Cotenti». Es a partir de l'antropònim Cotenti que miramen de relacionar les actuals restes de la necròpolis amb l'Alcanícia.

L'antic Cotenti apareix en el capbreu de 1373 diverses vegades com a nom d'una família musulmana que posseïa terres en el lloc de l'actual Potenti, nom amb el que també s'ha conegut l'antic poblament de l'Areneta i el seu entorn:

«Mofferrig alquotendi sarrahi manifesta una olivera la qual es al fossar dels moros...» (23).

«Juceff alqutenti... manifesta que ha una olivera al fossar del sarrahins...» (24).

«tem manifesta que te per en Castellet al fossar dels sarrahins...» (25).

«Mofferrig benali beneffacen... manifesta que ha al fossar una sort... affronta ab una sort den Abraffim alcotendi...» (26).

«Abraffim benmoferrig alcutendi manifesta... un troç de terra campa que ha alcaniçia...» (27).

Les quatre primeres declaracions confirmen l'estreta relació de propietat que hi ha entre les terres de la família dels Cotenti i el fossar dels moros. La cinquena relació, juntament amb la citada anteriorment (28), ens relaciona propietats de la família Cotenti amb l'Alcanícia.

Cotenti es pot relacionar fácilment amb el topònim Potenti. En el «Diccionario Geográfico de España» de 1957 trobem aquesta referència: «En el lugar denominado Potenti hay ruinas de una población romana» (29). Entre els actuals habitants de Benifallet encara és ben viu aquest topònim, i es poden sentir expressions com: «Lo poble que es diu lo Potenti és del temps dels moros». Es una creença generalitzada que a Potenti, antigament, hi vivien els moros, aspecte que està en contradició amb les fons escrites, que diuen que era de l'època romana (30). Però és precisament aquesta creença el que confirma la tesi de l'article del Dr. Míkel de Epalza citat al principi d'aquestes ratlles. Encara, però, un últim exemple de la vitalitat del topònim

(22) No en tinc cap més referència, per tant, no puc certificar si és o no és àrab.

(23) Capbreu 1373 , fol. 51

(24) Capbreu 1373, fol. 68.

(25) Capbreu 1373, fol. 69. Es el mateix declarant que el de la cita anterior. De nou observem la presència del nom Castellet en aquest indret.

(26) Capbreu 1373 , fol. 80

(27) Capbreu 1373, fol. 93. Es el mateix declarant que el de la nota 9.

(28) Vegeu de nou la cita n. ${ }^{\circ} 8$.

(29) Diccionario Geográfico de España, volum 4, pàgina 436 (1957).

(30) Vegeu les citacions $15 ; 29$. 
Potenti; es tracta de la Roca Potenti, situada en el riu, ben a prop de la riba i de l'Areneta, i que les actuals obres del pont han colgat.

Així doncs, sembla bastant clar que l'antiga Alcanícia és l'actual lloc anomenat Potenti o també l'Areneta. La tradició ha mostrat les restes del poblat com les d'un antic $\|$ oc de moros, volent indicar que, quan els musulmans vivien en aquestes terres, no residien a l'actual nucli de Benifallet, sinó a Potenti. Amb l'actual expressió, «allà hi vivien els moros», referint-se a une ruïnes que ja existien quan es van colonitzar aquestes terres pels àrabs, eis habitants de Benifallet han pretès desvincular-se d'aquell indret. Creuen que si no és lloc cristià, ha de ser moro, ja que el seu passat cultural més immediat, i també el que més ha perdurat en la memòria dels habitants d'aquestes terres, és el dels àrabs. Per tant, no ens ha d'estranyar que a ells atribueixin aquestes ruines.

Aquest punt de vista coindideix amb el de M. de Epalza quan diu: «Creemos que los ejemplos de este topònimo -es refereix als derivats de "kanîsa" - coinciden muchas veces con ruinas preislámicas y que los indígenas, ya islamizados, les llamaron iglesias cristianas por ignorar que clase de monumento eran y encontrar que este epíteto era el mas honorable para los edificios de sus antepasados, y posiblemente el menos comprometido para sus descendientes musulmanes» (31). Es a dir, la tradició cultural musulmana de Benifallet, va fer amb el seu passat històric el mateix que posteriorment farien els cristians amb el seu: negar-lo, considerat poc digne, per reafirmar-se en la nova cultura dominant.

A més, cal recordar que a Potenti també hi ha, al costat de les restes del poblat, la necròpolis, i que M. de Epalza es refereix a les partides anomenades Alcanícia, Alcaníssia, Canassia, Canissis,... com a llocs «de ruïnes identificades amb enterraments o amb llocs de culte pre-islàmics pels àraboparlants musulmans» (32). S'ignora si el fossar dels moros citat anteriorment i les restes de la necròpolis de Potenti es refereixen al mateix lloc. En el cas de no coincidir, no poden estar gaire apartats un de l'altre. Tampoc no es coneix l'extensió ni els límits de l'antiga Alcanícia. Però cap d'aquestes imprecisions no alteren la finalitat d'aquest escrit: situar l'Alcanícia de Benifallet i relacionar-la amb altres derivats de «kanîsa» a partir de l'article del Dr. M. de Epalza.

(31) MÍKEL DE EPALZA: Els mossàrabs valencians i els topónims derivats de «kanisas àrab, dins de la Miscel.lània d'homenatge a Enric Moreu-Rey, vol. II, pàgina 151, Barcelona, 1988. Cita extreta de M. DE EPALZA; E. LLOBREGAT: ¿Hubo mozárabes en tierras valencianas? Proceso de Islamización del Levante de la Peninsula (Sharq Al-Andalus), «Revista del Instituto de Estudios Alicantinos», XXXVI (1982), pàgina 26.

(32) M. DE EPALZA: E/s mossàrabs..., pàgina 152. 